\title{
Association Between Fat Distribution and Low Back Pain: Results From The Korean National Health and Nutrition Examination Survey
}

Minji Oh

Kyung Hee University

Jongyeon Kim

Kyung Hee University

Seunghoon Lee ( $\sim$ kmdoctorlee@gmail.com )

Kyung Hee University

Jae-Dong Lee

Kyung Hee University

Research Article

Keywords: Fat mass, Fat distribution, Obesity, Chronic low back pain

Posted Date: June 17th, 2021

DOI: https://doi.org/10.21203/rs.3.rs-612174/v1

License: (9) This work is licensed under a Creative Commons Attribution 4.0 International License.

Read Full License 


\section{Abstract}

Obesity is associated with chronic low back pain (CLBP), but the association between fat distribution and CLBP is currently unclear. We designed a cross-sectional study to evaluate the relationship between the two, including 10,606 people who participated in the Korean National Health and Nutrition Examination Survey. We estimated the regional fat distribution as well as waist circumference and body fat proportion, and compared the values in people with and without CLBP. We also stratified the estimates by sex and obesity status. The average waist circumference was not significantly different between the CLBP (80.8 $\mathrm{cm})$ and non-CLBP groups $(80.7 \mathrm{~cm}, \mathrm{p}=0.606)$. There were no statistically significant differences in the average fat proportion between the CLBP $(26.5 \%)$ and non-CLBP groups $(26.6 \%, p=0.631)$. The average regional fat distribution in the lower limbs was significantly higher in the CLBP $(31.9 \%, 95 \%$ confidence interval [CI]: [31.6, 32.2]) than in the CLBP groups (31.4\%, 95\% Cl: [31.2, 31.6], $\mathrm{p}<0.001)$; this pattern was more obvious in men with obesity. People, particularly men, with CLBP and obesity tend to have a higher fat mass distribution in the lower limbs than those without CLBP, suggesting that fat reductions in the lower body may aid in CLBP management.

\section{Introduction}

Low back pain (LBP), a musculoskeletal disorder that is commonly observed in clinical practice, affects physical activity and leads to quality of life deteriorations [1]. One in ten people, worldwide, have LBP at any time point, and $70-85 \%$ of people have an LBP episode at some time in their life [2]. The costs associated with LBP are enormous, leading to major economic burden for patients, the government, and health insurance companies [3]. As the etiology of LBP is complex, some factors related to its prevalence and incidence include the presence of comorbidities, lifestyle factors (e.g., smoking), occupational and psychosocial factors, physical inactivity [4,5], genetics [6], and sex [7]. Critical insights into the management and prevention of LBP may be gained with a more nuanced understanding of the related risk factors $[3,8]$.

Obesity is associated with various musculoskeletal conditions and is accountable for serious disability and an impaired quality of life [9]. While data on the association between obesity and LBP [10] are consistent across studies in which the former was defined based on body mass index (BMI), obesity status, as ascertained by BMI, may not convey sufficient information on LBP, as BMI is a composite of various factors, such as fat mass and lean mass; additionally, it does not provide meaningful information on whole-body fat distribution. Thus, it may be relevant to investigate the relationship between fat distribution and LBP.

Some previous studies have focused on the association of fat mass distribution with LBP. Brady et al. provided evidence on the crucial role of fat mass, especially android fat relative to gynoid fat, in back disability and pain [11]. While Hussain et al. showed that LBP-induced pain intensity and disability were related to body composition measures, such as fat mass, fat proportion, and waist circumference, they did not include sufficient information on the manner in which regional fat distribution is associated with 
LBP [12]. Another study found a weak association between high levels of body fat mass accumulation around the hips and an increased prevalence of chronic LBP in women [13]. None of the aforementioned studies quantified fat distribution using validated measurements.

Dual-energy X-ray absorptiometry (DXA) can overcome the limitations of the prior studies. It is a valid and reliable technique for the assessment of body composition [14], and can validly describe the populationlevel distribution of body composition in people with obesity [15]. The Korean National Health and Nutrition Examination Survey (KNHANES) collected DXA measurement data pertaining to each body part (head, trunk, and upper/lower limbs) in 2008-2011. Several studies have examined the relationship between chronic pain and obesity using KNHANES data. While one study reported on the association between CLBP and abdominal obesity, as assessed by waist circumference [16], another investigated that between LBP and metabolic syndrome [17]. However, to the best of our knowledge, no studies till date have examined the relationship between CLBP and regional fat distribution using DXA data.

Accordingly, we attempted to examine the relationship between fat distribution and CLBP, using the KNHANES IV data.

\section{Results}

\section{Characteristics of the study population}

Of the 11,503 participants who completed the health interview survey and health examination survey, we excluded 268 participants due to unavailability of data pertaining to DXA measurement or CLBP status. Then, we enrolled 10,606 participants after the exclusion of 629 patients aged $<19$ years (Fig. 1).

The weighted BMI average was $23.7 \mathrm{~kg} / \mathrm{m}^{2}$ (95\% confidence interval [Cl]: [23.5, 23.9]) in the people with CLBP and $23.5 \mathrm{~kg} / \mathrm{m}^{2}$ (95\% Cl: $\left.[23.4,23.6]\right)$ in those without CLBP. The weighted average total lean mass was $42.3 \mathrm{~kg}(95 \% \mathrm{Cl}:[41.7,42.9])$ in the people with CLBP, which was lower than that in those without $\operatorname{CLBP}(46.5 \mathrm{~kg}, 95 \% \mathrm{Cl}:[46.3,46.8])$.

The people with CLBP tended to have a lower level of education and income than those without CLBP. The proportion of white-collar workers was lower in the CLBP group than in the non-CLBP group (10.5\% vs. $24.7 \%$ ). The non-CLBP group comprised participants who tended to be younger (43.2 years vs. 54.8 years), live in Seoul (24.4\% vs. $12.7 \%$ ), and be male compared to the CLBP group (47.5\% vs. $67.6 \%$ ).

There were fewer current smokers ( $18.2 \%$ vs. $28.1 \%)$ and drinkers ( $43.6 \%$ vs. $61.2 \%)$ in the CLBP group. In the non-CLBP group, a larger number of people participated in vigorous physical activity $(18.6 \% \mathrm{vs}$. $17.1 \%)$, whereas only a small number of people showed moderate physical activity levels $(13.3 \% \mathrm{vs}$. $18.2 \%)$ compared to the values in the CLBP group.

The people with CLBP tended to have depression (11.4\% vs. $3.41 \%)$ and osteoporosis $(13.3 \%$ vs. $2.10 \%)$ compared to those without it. Detailed estimates are summarized in Table 1. 
Table 1

Characteristics of the Study Population According to CLBP Status (KNHANES IV, 2008-2009)
$\operatorname{CLBP}(n=$
1981)
No CLBP $(n=$
8625)

Unweighted

Weighted estimates

Unweighted

Weighted estimates

values $^{\text {a }}$

$[95 \% \mathrm{Cl}]^{\mathrm{b}}$

values $^{\text {a }}$

[95\% Cl] ${ }^{b}$

Anthropometric

factors

\begin{tabular}{|c|c|c|c|c|}
\hline BMI $\left(\mathrm{kg} / \mathrm{m}^{2}\right)$ & $\begin{array}{l}23.7(21.5, \\
25.8)\end{array}$ & $23.7[23.5,23.9]$ & $\begin{array}{l}23.3(21.2, \\
25.6)\end{array}$ & $23.5[23.4,23.6]$ \\
\hline $\begin{array}{l}\text { Total lean mass } \\
(\mathrm{kg})\end{array}$ & $\begin{array}{l}39.2(35.3 \\
46.0)\end{array}$ & $42.3[41.7,42.9]$ & $\begin{array}{l}43.3(37.3, \\
52.7)\end{array}$ & $46.5[46.3,46$ \\
\hline
\end{tabular}

\section{Sociodemographic factors}
Age (year)
$63(48,71)$
$54.8[53.6,55.9]$
$45(34,59)$
$43.2[42.6,43.8]$

Sex

Female

$1422(71.8)$

$67.6[65.3,69.9]$

4637 (53.8)

$47.5[46.6,48.5]$

\section{Education}

\begin{tabular}{lllll} 
Elementary & $1113(56.2)$ & $45.2[42.0,48.4]$ & $1897(22.0)$ & $16.0[14.7,17.2]$ \\
\hline Middle & $231(11.7)$ & $12.2[10.5,14.0]$ & $961(11.1)$ & $10.1[9.30,10.8]$ \\
\hline High & $423(21.4)$ & $28.3[25.2,31.5]$ & $3255(37.7)$ & $41.8[40.1,43.4]$ \\
\hline College & $214(10.8)$ & $14.2[11.8,16.6]$ & $2478(28.7)$ & $32.2[30.3,34.1]$ \\
NA & $0(0)$ & - & $34(0.394)$ & -
\end{tabular}

\section{Occupation}

\begin{tabular}{lllll} 
White-collar & $142(7.17)$ & $10.5[8.63,12.3]$ & $1804(20.9)$ & $24.7[23.3,26.1]$ \\
Blue-collar & $867(43.8)$ & $41.0[37.9,44.2]$ & $3465(40.2)$ & $39.1[37.4,40.9]$ \\
\hline Unemployed & $967(48.8)$ & $48.5[45.4,51.6]$ & $3294(38.2)$ & $36.2[34.8,37.5]$ \\
NA & $5(0.252)$ & - & $62(0.719)$ & -
\end{tabular}

Abbreviations: KNHANES, Korea National Health and Nutrition Examination Survey; CLBP, chronic low back pain; $\mathrm{Cl}$, confidence interval; $\mathrm{BMI}$, body mass index; NA, not available.

${ }^{a}$ Each unweighted value is either a median with an interquartile range or a count with its percentage.

${ }^{\mathrm{b}}$ Each weighted estimate is a counterpart of each unweighted one and was estimated from 10 imputed datasets. For nominal variables, it is an estimated percentage; for continuous variables, it is an estimated average, with its $95 \%$ confidence intervals. 

CLBP $(n=$
1981)
No CLBP ( $n=$
8625)

\section{Income}

Low

731 (36.9)

$29.5[26.7,32.3]$

1473 (17.1)

$13.9[12.6,15.2]$

Low-mid

461 (23.3)

$23.4[20.8,25.9]$

2098 (24.3)

$24.4[22.7,26.0]$

Mid-high

427 (21.6)

$25.0[22.1,27.8]$

2469 (28.6)

$30.7[29.0,32.5]$

High

346 (17.5)

$22.2[19.4,25.0]$

2448 (28.4)

$31.0[28.6,33.4]$

NA

$16(0.808)$

137 (1.59)

\section{Region}

Seoul

$151(7.62)$

$12.7[10.1,15.4]$

$1600(18.6)$

$24.4[22.1,26.8]$

\section{Health Behavior}

Currently smoking

$\begin{array}{lllll}\text { Yes } & 286(14.4) & 18.2[16.0,20.4] & 2066(24.0) & 28.1[27.0,29.3] \\ \text { NA } & 6(0.303) & - & 35(0.406) & -\end{array}$

Drinking

$\begin{array}{lllll}\text { Yes } & 748(37.8) & 43.6[40.8,46.4] & 4859(56.3) & 61.2[59.9,62.5] \\ \text { NA } & 3(0.151) & - & 29(0.336) & -\end{array}$

Physical activity

$\begin{array}{lllll}\text { Vigorous } & 326(16.5) & 17.1[15.1,19.2] & 1479(17.1) & 18.6[17.4,19.7] \\ \text { NA } & 3(0.151) & - & 34(0.394) & - \\ \text { Moderate } & 379(19.1) & 18.2[15.9,20.5] & 1204(14.0) & 13.3[12.3,14.4] \\ \text { NA } & 4(0.202) & - & 38(0.441) & - \\ \text { Walking } & 916(46.2) & 47.3[44.3,50.3] & 4004(46.4) & 46.7[45.4,48.1] \\ \text { NA } & 4(0.202) & - & 40(0.464) & -\end{array}$

\section{Comorbidity}

Abbreviations: KNHANES, Korea National Health and Nutrition Examination Survey; CLBP, chronic low back pain; $\mathrm{Cl}$, confidence interval; $\mathrm{BMI}$, body mass index; NA, not available.

a Each unweighted value is either a median with an interquartile range or a count with its percentage.

${ }^{\mathrm{b}}$ Each weighted estimate is a counterpart of each unweighted one and was estimated from 10 imputed datasets. For nominal variables, it is an estimated percentage; for continuous variables, it is an estimated average, with its $95 \%$ confidence intervals. 


\begin{tabular}{|lllll|}
\hline & CLBP $(n=$ & & \multicolumn{3}{l|}{ No CLBP $(n=$} \\
\hline 1981) & & 8625) & \\
\hline Depression & $234(11.8)$ & $11.4[9.61,13.1]$ & $331(3.84)$ & $3.41[2.93,3.88]$ \\
\hline Osteoporosis & $336(17.0)$ & $13.3[11.6,15.1]$ & $264(3.06)$ & $2.10[1.80,2.40]$ \\
\hline
\end{tabular}

Abbreviations: KNHANES, Korea National Health and Nutrition Examination Survey; CLBP, chronic low back pain; $\mathrm{Cl}$, confidence interval; $\mathrm{BMI}$, body mass index; $\mathrm{NA}$, not available.

a Each unweighted value is either a median with an interquartile range or a count with its percentage.

${ }^{\mathrm{b}}$ Each weighted estimate is a counterpart of each unweighted one and was estimated from 10 imputed datasets. For nominal variables, it is an estimated percentage; for continuous variables, it is an estimated average, with its $95 \%$ confidence intervals.

\section{Aim 1: Waist Circumference By Clbp Status}

Overall, there were no statistically significant differences in the estimated marginal average waist circumference values between the people with and without CLBP. The marginal average estimated in the people with obesity was $90.1 \mathrm{~cm}(95 \% \mathrm{Cl}$ : $[89.5,90.7])$ in the CLBP group and $89.9 \mathrm{~cm}(95 \% \mathrm{Cl}$ : [89.5, 90.3]) in the non-CLBP group; the difference was not statistically significant. Among the male participants with obesity, the estimated average waist circumference was $91.1 \mathrm{~cm}(95 \% \mathrm{Cl}:[90.1,92.1])$ in the people with CLBP and $92.2 \mathrm{~cm}(95 \% \mathrm{Cl}$ : $[91.7,92.7])$ in those without it; the difference was statistically significant $(p<0.05)$. However, we could not observe statistically significant differences in women with obesity or those without obesity (Table 2 ). 
Table 2

Estimated Marginal Average of Waist Circumference According to CLBP Status

\begin{tabular}{|c|c|c|c|c|c|}
\hline $\mathrm{BMl}, \mathrm{kg} / \mathrm{m}^{2}$ & Sex & $\begin{array}{l}\text { CLBP } \\
(\mathrm{cm},[95 \% \mathrm{Cl}])\end{array}$ & $\begin{array}{l}\text { No CLBP } \\
\text { (cm, }[95 \% \mathrm{Cl}])\end{array}$ & P-value ${ }^{a}$ & $P$ for $E^{\prime} M^{b}$ \\
\hline \multirow[t]{3}{*}{$>=25$} & Female & $88.3[87.5,89.2]$ & $87.9[87.3,88.5]$ & 0.328 & - \\
\hline & Male & $91.1[90.1,92.1]$ & $92.2[91.7,92.7]$ & 0.0493 & 0.0440 \\
\hline & Overall & $90.1[89.5,90.7]$ & $89.9[89.5,90.3]$ & 0.640 & - \\
\hline \multirow[t]{3}{*}{$<25$} & Female & $74.3[73.6,75.0]$ & $73.8[73.4,74.2]$ & 0.127 & - \\
\hline & Male & $78.9[77.9,79.9]$ & $79.2[78.9,79.6]$ & 0.470 & 0.139 \\
\hline & Overall & $76.6[76.0,77.2]$ & $76.5[76.2,76.8]$ & 0.702 & 0.908 \\
\hline Overall & & $80.8[80.3,81.3]$ & $80.7[80.3,81.0]$ & 0.606 & - \\
\hline \multicolumn{6}{|c|}{$\begin{array}{l}\text { Abbreviations: CLBP, chronic low back pain; Cl, confidence interval; BMI, body mass index; EMM, } \\
\text { effect measure modification. }\end{array}$} \\
\hline \multicolumn{6}{|c|}{$\begin{array}{l}\text { a The } p \text {-values are used to test the hypothesis that the marginal averages of the two groups are the } \\
\text { same. }\end{array}$} \\
\hline \multicolumn{6}{|c|}{$\begin{array}{l}\mathrm{b} \text { The } \mathrm{p} \text {-values are considered to test the hypothesis that the differences of the marginal averages } \\
\text { estimated in the CLBP and non-CLBP groups are the same, on comparing the female and male } \\
\text { participants; or a BMI lower than } 25 \mathrm{~kg} / \mathrm{m}^{2} \text { and that higher than or equal to } 25 \mathrm{~kg} / \mathrm{m}^{2} \text {. }\end{array}$} \\
\hline
\end{tabular}

\section{Aim 2: Body Fat Proportion By Clbp Status}

The estimated marginal average of fat proportion against the total body weight did not significantly differ by CLBP status. When this value was estimated within people with obesity, it was found to be statistically significantly lower in the people with CLBP than in those without it $(30.7 \%$ vs. $31.3 \%, p<0.05)$. This pattern was more obvious in men than in women. In men with obesity, the estimated marginal average of body fat proportion was lower in the CLBP group $(25.7 \%, 95 \% \mathrm{Cl}$ : $[24.8,26.5])$ than in the non-CLBP group $(26.6 \%, 95 \% \mathrm{Cl}:[26.0,27.3])$; the difference was statistically significant $(p<0.01)$. On the other hand, in women with obesity, there was no statistically significant difference in the comparison of the CLBP and non-CLBP groups $(p=0.0598)$. However, we could not identify statistically significant differences within the people without obesity (Table 3 ). 
Table 3

Estimated Marginal Average of Fat Proportion against Body Weight by CLBP Status

\begin{tabular}{|c|c|c|c|c|c|}
\hline BMI, kg/m² & Sex & $\begin{array}{l}\text { CLBP } \\
(\%,[95 \% \mathrm{Cl}])\end{array}$ & $\begin{array}{l}\text { No CLBP } \\
(\%,[95 \% \mathrm{Cl}])\end{array}$ & P-value ${ }^{a}$ & $P$ for $E^{\prime} M^{b}$ \\
\hline \multirow[t]{3}{*}{$>=25$} & Female & $35.4[34.9,35.9]$ & $35.9[35.5,36.3]$ & 0.0598 & - \\
\hline & Male & $25.7[24.8,26.5]$ & $26.6[26.0,27.3]$ & 0.00784 & 0.256 \\
\hline & Overall & $30.7[30.2,31.2]$ & $31.3[30.9,31.7]$ & 0.0107 & - \\
\hline \multirow[t]{3}{*}{$<25$} & Female & $28.9[28.4,29.4]$ & $28.8[28.4,29.3]$ & 0.705 & - \\
\hline & Male & $20.3[19.6,21.0]$ & $20.0[19.5,20.4]$ & 0.279 & 0.513 \\
\hline & Overall & $24.6[24.2,25.0]$ & $24.4[24.2,24.7]$ & 0.448 & 0.00833 \\
\hline Overall & & $26.5[26.1,26.9]$ & $26.6[26.3,26.8]$ & 0.631 & - \\
\hline \multicolumn{6}{|c|}{$\begin{array}{l}\text { Abbreviations: CLBP, chronic low back pain; } \mathrm{Cl} \text {, confidence interval; BMI, body mass index; EMM, } \\
\text { effect measure modification. }\end{array}$} \\
\hline \multicolumn{6}{|c|}{$\begin{array}{l}\text { a The } p \text {-values considered are to test the hypothesis that the marginal averages of the two groups are } \\
\text { the same. }\end{array}$} \\
\hline \multicolumn{6}{|c|}{$\begin{array}{l}\mathrm{b} \text { The } \mathrm{p} \text {-values are considered to test the hypothesis that the differences of the marginal averages } \\
\text { estimated in the CLBP and non-CLBP groups are the same, on comparing female and male } \\
\text { participants; or BMI lower than } 25 \mathrm{~kg} / \mathrm{m}^{2} \text { and that higher than or equal to } 25 \mathrm{~kg} / \mathrm{m}^{2} \text {. }\end{array}$} \\
\hline
\end{tabular}

\section{Aim 3: Regional Fat Distribution Vs. Clbp Status}

The estimated marginal average of the regional fat distribution in the lower limbs was significantly higher in the people with $\operatorname{CLBP}(31.9 \%, 95 \% \mathrm{Cl}$ : [31.6, 32.2]) than in those without CLBP $(31.4 \%, 95 \% \mathrm{Cl}$ : [31.2, 31.6], $p<0.001)$. This pattern was more obvious in the people with obesity. Among those with obesity, the estimated average was 30.2\% (95\% Cl: $[29.8,30.6])$ in the CLBP group and $29.4 \%$ (95\% Cl: $[29.1,29.6])$ in the non-CLBP group $(p<0.001)$. The same pattern was observed in both sexes (Table 4, Fig. 2$)$. 
Table 4

Estimated Marginal Average of Fat Distribution against Total Body Fat in Each Body Part

\begin{tabular}{|c|c|c|c|c|c|c|}
\hline Body part & $\begin{array}{l}\mathrm{BMl}, \\
\mathrm{kg} / \mathrm{m}^{2}\end{array}$ & Sex & $\begin{array}{l}\text { CLBP } \\
(\%, 95 \% \mathrm{Cl})\end{array}$ & $\begin{array}{l}\text { No CLBP } \\
(\%, 95 \% \mathrm{Cl})\end{array}$ & P-value ${ }^{a}$ & $\begin{array}{l}\mathrm{P} \text { for } \mathrm{EMM} \\
\mathrm{b}\end{array}$ \\
\hline \multirow[t]{6}{*}{$\begin{array}{l}\text { Upper } \\
\text { limbs }\end{array}$} & $>=25$ & Female & $\begin{array}{l}12.5[12.3 \\
12.7]\end{array}$ & $\begin{array}{l}12.4[12.3 \\
12.6]\end{array}$ & 0.373 & - \\
\hline & & Male & $\begin{array}{l}\text { 10.3 [9.96, } \\
10.6]\end{array}$ & $\begin{array}{l}10.1 \text { [9.99, } \\
10.3]\end{array}$ & 0.401 & 0.818 \\
\hline & & Overall & $\begin{array}{l}11.4[11.2, \\
11.6]\end{array}$ & $\begin{array}{l}11.3[11.1 \\
11.4]\end{array}$ & 0.104 & - \\
\hline & $<25$ & Female & $\begin{array}{l}12.3[12.1, \\
12.5]\end{array}$ & $\begin{array}{l}12.2[12.1, \\
12.4]\end{array}$ & 0.324 & - \\
\hline & & Male & $\begin{array}{l}\text { 10.5 [10.3, } \\
10.7]\end{array}$ & $\begin{array}{l}10.2[10.0 \\
10.3]\end{array}$ & 0.00242 & 0.0493 \\
\hline & & Overall & $\begin{array}{l}11.4[11.2, \\
11.5]\end{array}$ & $\begin{array}{l}11.2[11.1, \\
11.3]\end{array}$ & 0.0217 & 0.947 \\
\hline Overall & & & $\begin{array}{l}11.4[11.3, \\
11.5]\end{array}$ & $\begin{array}{l}11.2[11.1, \\
11.3]\end{array}$ & 0.00712 & - \\
\hline \multirow[t]{6}{*}{$\begin{array}{l}\text { Lower } \\
\text { limbs }\end{array}$} & $>=25$ & Female & $\begin{array}{l}31.4[30.9 \\
31.8]\end{array}$ & $\begin{array}{l}30.2[29.8 \\
30.6]\end{array}$ & $3.12 \mathrm{e}-06$ & - \\
\hline & & Male & $\begin{array}{l}29.6[28.9, \\
30.3]\end{array}$ & $\begin{array}{l}28.2[27.9, \\
28.6]\end{array}$ & $7.88 \mathrm{e}-05$ & 0.592 \\
\hline & & Overall & $\begin{array}{l}30.2[29.8 \\
30.6]\end{array}$ & $\begin{array}{l}29.4 \text { [29.1, } \\
29.6]\end{array}$ & 0.000110 & - \\
\hline & $<25$ & Female & $\begin{array}{l}34.1[33.6, \\
34.6]\end{array}$ & $\begin{array}{l}34.4[34.1 \\
34.8]\end{array}$ & 0.197 & - \\
\hline & & Male & $\begin{array}{l}31.2[30.7, \\
31.7]\end{array}$ & $\begin{array}{l}30.2[29.9 \\
30.4]\end{array}$ & $4.93 e-05$ & 0.000187 \\
\hline & & Overall & $\begin{array}{l}32.6[32.3, \\
33.0]\end{array}$ & $\begin{array}{l}32.3[32.1 \\
32.5]\end{array}$ & 0.0600 & 0.0430 \\
\hline Overall & & & $\begin{array}{l}31.9[31.6, \\
32.2]\end{array}$ & $\begin{array}{l}31.4[31.2, \\
31.6]\end{array}$ & 0.000891 & - \\
\hline Trunk & $>=25$ & Female & $\begin{array}{l}52.2[51.7, \\
52.7]\end{array}$ & $\begin{array}{l}53.7[53.2, \\
54.1]\end{array}$ & $1.58 \mathrm{e}-07$ & - \\
\hline
\end{tabular}

a The $p$-values are to test the hypothesis that the marginal averages of the two groups are the same.

$\mathrm{b}$ The $\mathrm{p}$-values are to test the hypothesis that the differences of the marginal averages estimated in the CLBP and non-CLBP groups are the same, on comparing female and male participants; or BMI lower than $25 \mathrm{~kg} / \mathrm{m}^{2}$ and that higher than or equal to $25 \mathrm{~kg} / \mathrm{m}^{2}$. 


\begin{tabular}{|c|c|c|c|c|c|c|}
\hline Body part & $\begin{array}{l}\mathrm{BMl}, \\
\mathrm{kg} / \mathrm{m}^{2}\end{array}$ & Sex & $\begin{array}{l}\text { CLBP } \\
(\%, 95 \% \mathrm{Cl})\end{array}$ & $\begin{array}{l}\text { No CLBP } \\
(\%, 95 \% \mathrm{Cl})\end{array}$ & P-value ${ }^{a}$ & $\begin{array}{l}\text { P for EMM } \\
\text { b }\end{array}$ \\
\hline & & Male & $\begin{array}{l}53.5[52.7 \\
54.3]\end{array}$ & $\begin{array}{l}55.4[54.9 \\
55.9]\end{array}$ & 8.30e-06 & 0.371 \\
\hline & & Overall & $\begin{array}{l}53.0[52.5, \\
53.4]\end{array}$ & $\begin{array}{l}54.5[54.2, \\
54.8]\end{array}$ & $1.14 \mathrm{e}-09$ & - \\
\hline & $<25$ & Female & $\begin{array}{l}48.4[47.8, \\
48.9]\end{array}$ & $\begin{array}{l}48.3[47.9, \\
48.7]\end{array}$ & 0.796 & - \\
\hline & & Male & $\begin{array}{l}49.5[48.8 \\
50.1]\end{array}$ & $\begin{array}{l}50.7[50.4, \\
51.1]\end{array}$ & 0.000228 & 0.00285 \\
\hline & & Overall & $\begin{array}{l}49.0[48.7, \\
49.4]\end{array}$ & $\begin{array}{l}49.5[49.3 \\
49.7]\end{array}$ & 0.0229 & 0.000417 \\
\hline Overall & & & $\begin{array}{l}50.3[49.9, \\
50.6]\end{array}$ & $\begin{array}{l}51.0[50.8, \\
51.3]\end{array}$ & $2.42 \mathrm{e}-06$ & - \\
\hline \multicolumn{7}{|c|}{ a The p-values are to test the hypothesis that the marginal averages of the two groups are the same. } \\
\hline \multicolumn{7}{|c|}{$\begin{array}{l}\mathrm{b} \text { The } p \text {-values are to test the hypothesis that the differences of the marginal averages estimated in } \\
\text { the CLBP and non-CLBP groups are the same, on comparing female and male participants; or BMI } \\
\text { lower than } 25 \mathrm{~kg} / \mathrm{m}^{2} \text { and that higher than or equal to } 25 \mathrm{~kg} / \mathrm{m}^{2} \text {. }\end{array}$} \\
\hline
\end{tabular}

The estimate in the upper limbs was statistically significantly higher in the people with CLBP $(11.4 \%$, $95 \%$ Cl: $[11.3,11.5])$ than in those without it $(11.2 \%, 95 \% \mathrm{Cl}:[11.1,11.3], p<0.01)$. Among those without obesity, the estimated average regional fat proportion in the upper limbs was statistically significantly higher in the people with CLBP $(11.4 \%, 95 \% \mathrm{Cl}:[11.2,11.5])$ than in those without it $(11.2 \%, 95 \% \mathrm{Cl}$ : [11.1, $11.3], p<0.05)$. The same pattern was observed in men without obesity $(p<0.005)$ but not in women without obesity or in people with obesity (Table 4).

\section{Discussion}

The findings of our study, which included a nationwide representative adult population from South Korea, suggest that the significance of regional fat mass distribution is high, compared to that of waist circumference and body fat proportion, in the context of CLBP. People with CLBP tend to have a higher fat distribution in the limbs than those without it. Specifically, among people with obesity, the regional fat distribution in the lower limbs is higher in people with CLBP; among people without obesity, the regional fat distribution in the upper limbs was higher in the CLBP group. These patterns were more obvious among men than among women.

Some studies have demonstrated the presence of a relationship between waist circumference and CLBP. One study suggested that the likelihood of LBP development increases significantly in women with a high waist circumference [23], while another showed that LBP was related to a higher waist-hip ratio and BMI 
in men, with a stronger trend toward having a higher fat mass index [24]. However, our study that used KNHANES IV data could not identify a significant relationship between waist circumference and CLBP, except in men with obesity.

Some previous studies focused on the distribution of fat mass for the investigation of the relationship with LBP. A population-based longitudinal study showed that fat mass and fat distribution were affirmatively correlated with the intensity and disability associated with back pain [12]. Another found that higher levels of fat mass deposition around the hips were weakly related to increases in the prevalence of CLBP in women through the investigation of 1,128 female twins [13]. There exists evidence on the important role of fat mass, specifically android fat relative to gynoid fat, in back pain and disability [11]. We found that the total fat mass relative to the total body weight did not differ by CLBP status, except in men with obesity; however, people with CLBP and obesity had a higher fat distribution in the lower limbs than those without CLBP. This tendency was more obvious in men than in women. These results imply that the regional fat distribution in the lower limbs may convey more important information on CLBP than waist circumference and fat proportion in people with obesity, regardless of sex.

Few studies have examined the manner in which fat distribution affects CLBP. One study proposed that regional fat distribution may play an important role in the etiology of adiposity-related disease [25]. Another study demonstrated the relationship between fat mass and LBP by suggesting that some systemic and biomechanical factors related with obesity contribute to the pathogenesis of LBP [12]. In this light, certain confounding factors associated with regional fat distribution in the lower limbs may play a major role in the pathogenesis of CLBP. Increased intermuscular adipose tissue (IMAT) in the lower limbs may be a possible factor in the association of CLBP with regional fat distribution among people with obesity. IMAT is detected under the muscle fascia and is usually considered ectopic fat. Muscle injury, obesity, inactivity, disease status, and age are factors related to increased IMAT values. These increases in the IMAT levels may also cause a larger number of muscle, metabolic, and mobility dysfunctions [26]. As an example, a previous study examined the relationship between IMAT and lower limb muscle strength and power in elderly people [27]. If the fat distribution in the lower limbs increases in association with obesity, the probability of IMAT occurrence in the lower limb muscles too may rise, which may lead to lower extremity muscle weakness and susceptibility to CLBP. Some studies have examined the relationship between muscle power in the lower extremities and LBP. One study emphasized that muscle weakness and an imbalance in the muscle power ratio of the quadriceps femoris and hamstring play important roles in the prevalence of LBP along with muscle weakness and imbalance in the lumbar muscles [28]. Another showed that the hamstring tends to be particularly weak in patients with LBP [29].

A Spanish twin study suggested that early-life environmental factors or genetic factors may confound the association between the waist-hip ratio and CLBP [13]. Considering the similar patterns observed in the present study, our results may have arisen from confounders related to both fat distribution in the lower limbs and the pathogenesis of CLBP. Of note, while the pattern we observed was obvious in the male participants with obesity, the aforementioned Spanish twin study targeted only women. The pattern may have been more visible in men due to differences in the body composition between men and women. Sex 
differences in the fat phenotypes are presumably established by a complicated interaction of genetic, epigenetic, and hormonal factors [30]. Women tend to accumulate a large amount of adipose tissue in the hips and thighs, and have higher percentage body fat values compared to men. These basic differences in physical characteristics between the sexes are thought to influence the variations in the distribution of fat in the lower limbs between men and women. Further studies should focus on the manner in which sex and race affect the association between fat distribution and CLBP pathogenesis.

This study has some limitations. First, while DXA is a useful tool for the determination of body composition, it cannot accurately distinguish between different types of fat, such as subcutaneous fat and visceral fat. For this reason, it was challenging to discuss further which type of fat tissue was associated with the patterns observed in this study. Second, due to the lack of research on the mechanism of upper limb obesity, it was difficult to interpret our results on the relationship between the fat distribution in the upper limbs and LBP in the absence of obesity. Third, we could not include information on the physiological state related to the distribution of body fat, such as menopause, to explain the difference between male and female sex.

Nevertheless, this study has the following strengths. First, it investigated the relationship between fat distribution and CLBP using KNHANES data, so the results represent the general population of Korea. In addition, rather than simply examine the relationship between the absolute amount of fat mass and CLBP, we explored the regional fat distribution. To the best of our knowledge, this study is the first to demonstrate the relationship between the fat distribution in the lower limbs and CLBP. Clinically, in the case of CLBP patients with a BMI of $25 \mathrm{~kg} / \mathrm{m}^{2}$ or higher, it may be helpful to provide treatment and encourage participation in exercise with the aim of reducing the fat percentage in the lower body, rather than simply focusing on weight loss.

In this nationwide representative sample of Korean adults, we found that people with CLBP and obesity tend to have a higher fat distribution in the lower limbs than those without CLBP; this pattern was particularly evident in our male participants. Our findings suggest that the fat distribution in the lower limbs provides a greater degree of information on CLBP than simple waist circumference in people with obesity. Future large-scale cohort studies or clinical trials should confirm whether fat mass reductions in the lower limbs can prove effective in CLBP treatment.

\section{Materials And Methods}

\section{Study population}

The study population included participants of the KNHANES IV, 2008-2009, which comprised a health interview survey, a health examination survey, and a nutrition survey. The health interview survey included items pertaining to sociodemographic status and health-related behaviors, and was used for obtaining data on morbidity, including self-reported CLBP status. The health examination survey comprised items 
on waist circumference and BMI as well as DXA measurements, from which we quantified regional fat mass.

Although the KHNAHES IV was initiated in 2007, the use of DXA examination was started only in the second half of 2008; accordingly, we included observations from the period after 2008. The KNHANES V (2010-2012) also conducted DXA, but the health interview survey lacked any questions on prevalent CLBP. Therefore, our study population was limited to the individuals included in the KNHANES IV, 20082009.

In this population, we included people with data from both the health interview survey and health examination survey. We excluded those without DXA measurements or information on CLBP status. Also excluded were people aged 18 years or younger, since the minimum age of those with CLBP data was 19 years, although the KNHANES IV targeted citizens aged 10 years or older.

\section{DXA measurements}

DXA uses X-ray of two energy levels with different absorptivity to tissue components; in this manner, it quantifies fat mass, lean mass, and bone mass [18]. The KNHANES IV gathered data on the fat, bone, or lean mass of each body part (upper limbs, lower limbs, trunk, and head), as measured by DXA (DiscoveryW fan beam densitometer, Hologic, Inc., USA). We combined the measurements of the left and right into one value and did not use the measurement of the head itself, except for the total mass.

With the DXA measurements, we examined two aspects of obesity: body fat proportion against total body weight and regional fat distribution against total body fat; the former for the measurement of relative fat mass and the latter for the assessment of the manner in which the total fat mass is distributed along the whole body.

\section{Outcomes}

Of the aforementioned data, those pertaining waist circumference, body fat proportion, and regional fat distribution were used for the assessment of obesity status in three different ways. The waist circumference represents the apparent fat distribution at the trunk and was derived from the health examination survey (Aim 1). Data on body fat proportion and regional fat distribution were obtained using DXA. Body fat proportion signifies the total fat mass relative to the total weight (Aim 2), while regional fat distribution pertains to the fat mass distribution in each body part, which we defined as the regional fat mass divided by the total fat mass (head, trunk, and lower/upper limbs; Aim 3)

\section{Exposure and covariates}

Participants were assumed to have CLBP if they answered 'yes' to the following question in the health interview survey: "Have you experienced LBP persisting for three months or more in the most recent year?" 
For Aim 1, we adjusted for sociodemographic factors (sex, age, education, occupation, household income, and region), health behaviors (smoking, drinking, and physical activity), and comorbidities (osteoporosis and depression). Region was included as a binary variable (Seoul vs. the other areas), although it originally had 16 levels in the data. Participants were considered smokers if they had a smoking habit at the time, or had smoked five or more packs of cigarettes in their life. The variable for drinking identified people who had consumed one or more glasses of alcohol per month during the most recent year. For physical activity, we used three variables. One pertained to whether a participant partook in at least 20 minutes of vigorous physical activity three or more days a week, while another was related to participation in at least 30 minutes of moderate physical activity five or more days a week. The third variable was associated with walking for at least 30 minutes five or more days a week. Comorbidities were determined by the response to a question in the health interview survey about whether participants had experienced a condition for three or more months in the most recent year. Participants with a BMI higher or equal to $25 \mathrm{~kg} / \mathrm{m}^{2}$ were assigned to the obesity group according to the guideline for obesity diagnosis in Korea [19].

For Aims 2 and 3, we included the total lean body mass in addition to the aforementioned covariates. This allowed to obtain estimates conditional on the same total lean body mass. In other words, we tried to make estimates within people with similar body sizes except for fat mass.

\section{Statistical analysis}

We employed linear models to estimate average waist circumferences, body fat proportions, or regional fat proportions by CLBP status. For each aim, we assumed three models. First, we only included covariates as mentioned above for the estimation of averages by CLBP status conditional on the values of the covariates. The second model included an interaction term in the form of BMI category and CLBP status for the obtainment of estimates stratified by BMI category. For the third model, we added the interaction terms of BMI category, sex, and CLBP status for stratified estimates by sex and BMI category.

Following this, we calculated the marginal averages in each stratum. We first set sex, BMI category, or CLBP status to a value of each stratum and obtained predictions based on each model. Then, we averaged the predicted values, which is the marginal average of each stratum. For example, with the model including the interaction term of CLBP status and BMI category, we calculated the marginal average of either waist circumference, body fat proportion, or regional fat distribution in every combination of CLBP status (yes vs. no) and BMI category (lower than $25 \mathrm{~kg} / \mathrm{m}^{2}$ vs. $25 \mathrm{~kg} / \mathrm{m}^{2}$ or higher).

We conducted a hypothesis test to compare the marginal averages in the CLBP and non-CLBP groups. Another hypothesis test was conducted to test for sex- or BMI category-related differences in the marginal averages between the two groups. A p-value lower than 0.05 was assumed to be statistically significant.

To handle missing data, we employed the multiple imputation approach. Specifically, we imputed missing values using an $\mathrm{R}$ package, Amelia (version 1.7.6) [20] and created 10 imputed datasets. Using the 
imputed datasets, we performed the analyses, as described above, and combined the results, considering the variance among the estimates from the imputed datasets.

To account for the survey design of the KNHANES IV, we used the 'survey' package (version 4.0) with R 4.0.2. [21, 22].

\section{Ethics approval and consent to participate}

The Institutional Review Board (IRB) of the Korea Centers for Disease Control and Prevention (KCDC) approved the KNHANES survey protocol (No:2007-02CON-04-P, 2008-04EXP-01-C, 2009-01CON-03-2C), and all participants of the KNHANES signed a written informed consent form. This study was conducted in accordance with the ethical guidelines of the Declaration of Helsinki for medical research involving human research participants.

\section{Abbreviations}

LBP, low back pain; CLBP, chronic low back pain; $\mathrm{Cl}$, confidence interval; BMI, body mass index; KNHANES, Korea National Health and Nutrition Examination Survey; DXA, dual-energy X-ray absorptiometry; IMAT, intermuscular adipose tissue

\section{Declarations}

\section{Consent for publication}

Not applicable

\section{Availability of data and materials}

The datasets of this study are publicly available, and the analyzed data are available from the corresponding author on reasonable request.

\section{Competing interests}

The authors declare that they have no competing interests.

\section{Authors' contributions}

MO performed the data interpretation and wrote the first draft of the manuscript. JK performed the data analysis and wrote the manuscript. JDL contributed to the data interpretation and edited the manuscript. SL made plan and design the study, obtained funding, and edited the manuscript. All authors read and approved the final version of the manuscript.

\section{Acknowledgements}


We would also like to thank Dr Ju Hyuk Yim for his suggestions on clinical interpretation.

\section{References}

1. Hartvigsen J, Hancock MJ, Kongsted A, Louw Q, Ferreira ML, Genevay S, et al. What low back pain is and why we need to pay attention. Lancet. 391, 2356-67 (2018).

2. Hoy D, March L, Brooks P, Blyth F, Woolf A, Bain C, et al. The global burden of low back pain: estimates from the Global Burden of Disease 2010 study. Ann Rheum Dis. 73, 968-74 (2014).

3. Hancock MJ, Maher CM, Petocz P, Lin C-WC, Steffens D, Luque-Suarez A, et al. Risk factors for a recurrence of low back pain. Spine J. 15, 2360-8 (2015).

4. Ferreira GD, Silva MC, Rombaldi AJ, Wrege ED, Siqueira FV, Hallal PC. Prevalence and associated factors of back pain in adults from southern Brazil: a population-based study. Rev Bras Fisioter. 15, $31-6$ (2011).

5. Manchikanti L, Singh V, Falco FJE, Benyamin RM, Hirsch JA. Epidemiology of low back pain in adults. Neuromodulation. 17, 3-10 (2014).

6. Junqueira DRG, Ferreira ML, Refshauge K, Maher CG, Hopper JL, Hancock M, et al. Heritability and lifestyle factors in chronic low back pain: results of the Australian twin low back pain study (The AUTBACK study). Eur J Pain. 18, 1410-8 (2014).

7. Al Amer HS. Low back pain prevalence and risk factors among health workers in Saudi Arabia: A systematic review and meta-analysis. J Occup Health. 62, e12155 (2020).

8. Parreira P, Maher CG, Steffens D, Hancock MJ, Ferreira ML. Risk factors for low back pain and sciatica: an umbrella review. Spine J. 18, 1715-21 (2018).

9. Anandacoomarasamy A, Caterson I, Sambrook P, Fransen M, March L. The impact of obesity on the musculoskeletal system. Int J Obes (Lond). 32, 211-22 (2008).

10. Shiri R, Karppinen J, Leino-Arjas P, Solovieva S, Viikari-Juntura E. The association between obesity and low back pain: a meta-analysis. Am J Epidemiol. 171, 135-54 (2010).

11. Brady SRE, Urquhart DM, Hussain SM, Teichtahl A, Wang Y, Wluka AE, et al. High baseline fat mass, but not lean tissue mass, is associated with high intensity low back pain and disability in community-based adults. Arthritis Res Ther. 21, 165 (2019).

12. Hussain SM, Urquhart DM, Wang Y, Shaw JE, Magliano DJ, Wluka AE, et al. Fat mass and fat distribution are associated with low back pain intensity and disability: results from a cohort study. Arthritis Res Ther. 19, 26 (2017).

13. Dario AB, Ferreira ML, Refshauge K, Sánchez-Romera JF, Luque-Suarez A, Hopper JL, et al. Are obesity and body fat distribution associated with low back pain in women? A population-based study of 1128 Spanish twins. Eur Spine J. 25, 1188-95 (2016).

14. Schubert MM, Seay RF, Spain KK, Clarke HE, Taylor JK. Reliability and validity of various laboratory methods of body composition assessment in young adults. Clin Physiol Funct Imaging. 39, 150-9 (2019). 
15. LaForgia J, Dollman J, Dale MJ, Withers RT, Hill AM. Validation of DXA body composition estimates in obese men and women. Obesity (Silver Spring). 17, 821-6 (2009).

16. Choi EY. The Association of Low Back Pain with Obesity and Abdominal Obesity among Koreans Aged 50 Years or More. Korean J Health Promot. 18, 119-26 (2018).

17. Ha JY. Evaluation of metabolic syndrome in patients with chronic low back pain: using the fourth Korea national health and nutrition examination survey data. Chonnam Med J. 47, 160-4 (2011).

18. Plank LD. Dual-energy X-ray absorptiometry and body composition. Current Opinion in Clinical Nutrition \& Metabolic Care. 8, 305-9 (2005).

19. Seo MH, Lee W-Y, Kim SS, Kang J-H, Kang J-H, Kim KK, et al. 2018 Korean Society for the Study of Obesity Guideline for the Management of Obesity in Korea. J Obes Metab Syndr. 28, 40-5 (2019).

20. Honaker J, King G, Blackwell M. Amelia II: A Program for Missing Data. Journal of Statistical Software. 45, 1-47 (2011).

21. R Core Team. R: A Language and Environment for Statistical Computing. R Foundation for Statistical Computing. https://www.R-project.org (2020).

22. Lumley T. Analysis of Complex Survey Samples. Journal of Statistical Software. 9, 1-19 (2004).

23. Han TS, Schouten JS, Lean ME, Seidell JC. The prevalence of low back pain and associations with body fatness, fat distribution and height. Int J Obes Relat Metab Disord. 21, 600-7 (1997).

24. Chou L, Brady SRE, Urquhart DM, Teichtahl AJ, Cicuttini FM, Pasco JA, et al. The Association Between Obesity and Low Back Pain and Disability Is Affected by Mood Disorders: A PopulationBased, Cross-Sectional Study of Men. Medicine (Baltimore). 95, e3367 (2016).

25. Santhanam P, Rowe SP, Dias JP, Ahima RS. Relationship between DXA measured metrics of adiposity and glucose homeostasis; An analysis of the NHANES data. PLoS One. 14, e0216900 (2019).

26. Addison O, Marcus RL, Lastayo PC, Ryan AS. Intermuscular fat: a review of the consequences and causes. Int J Endocrinol. 309570 (2014).

27. Waters DL. Intermuscular Adipose Tissue: A Brief Review of Etiology, Association With Physical Function and Weight Loss in Older Adults. Ann Geriatr Med Res. 23, 3-8 (2019).

28. Bu KH, Oh TY. Effects of visual information on joint angular velocity of trunk and lower extremities in sitting and squat motion. J Kor Phys Ther. 27, 89-95 (2015).

29. K. Kim, E. Kim, D. Lee. Effects of PNF patterns exercise on pain, functional disability and fear avoidance belief in chronic low back pain patients. J Kor Soc Phys Ther. 26, 110-6 (2014).

30. Cuello AC. Glycosphingolipids that can regulate nerve growth and repair. Adv Pharmacol. 21, 1-50 (1990).

\section{Figures}




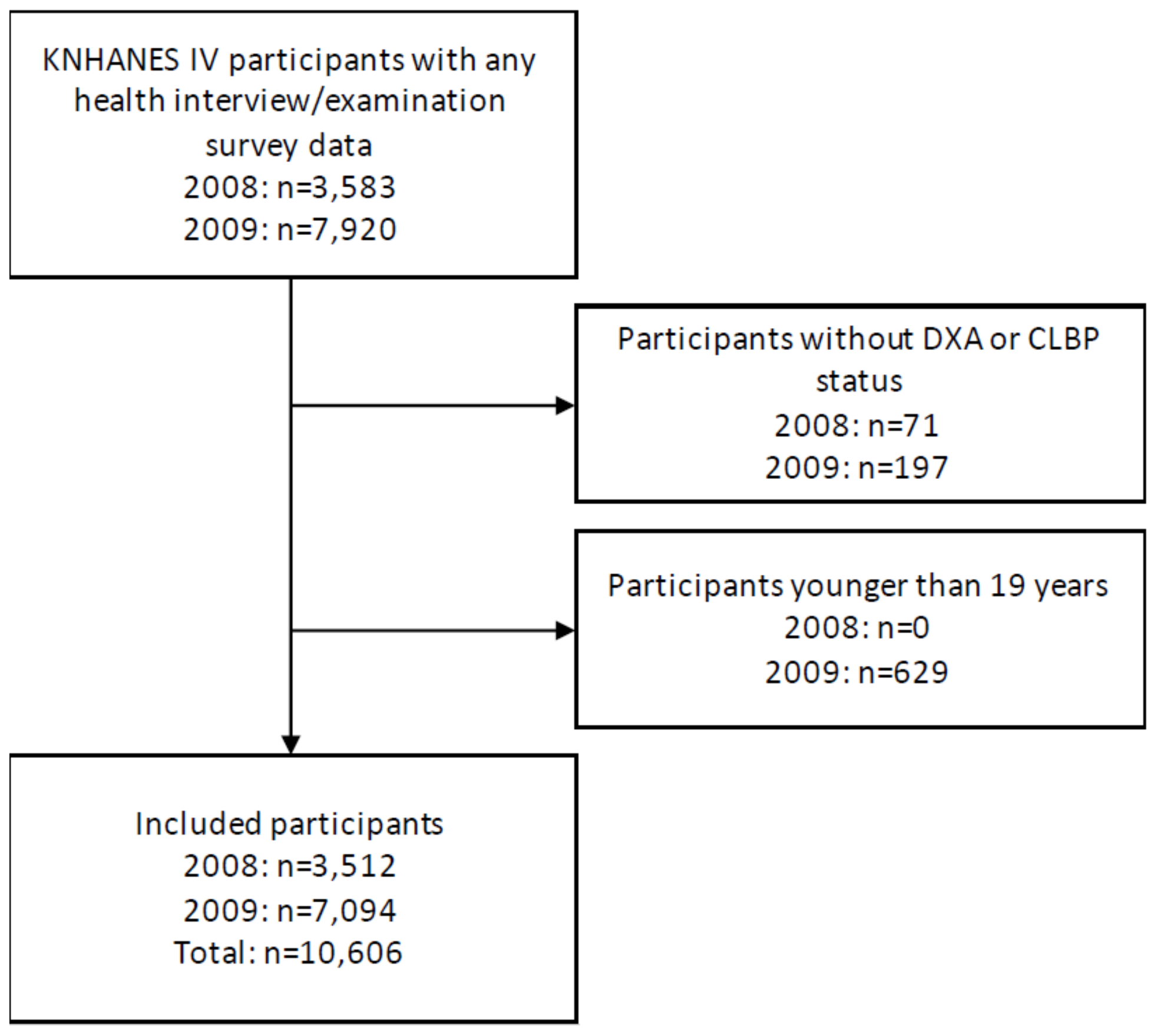

\section{Figure 1}

Flow chart of participant enrollment. Abbreviations: KNHANES, Korean National Health and Nutrition Examination Survey; DXA, dual-energy X-ray absorptiometry; CLBP, chronic low back pain. 

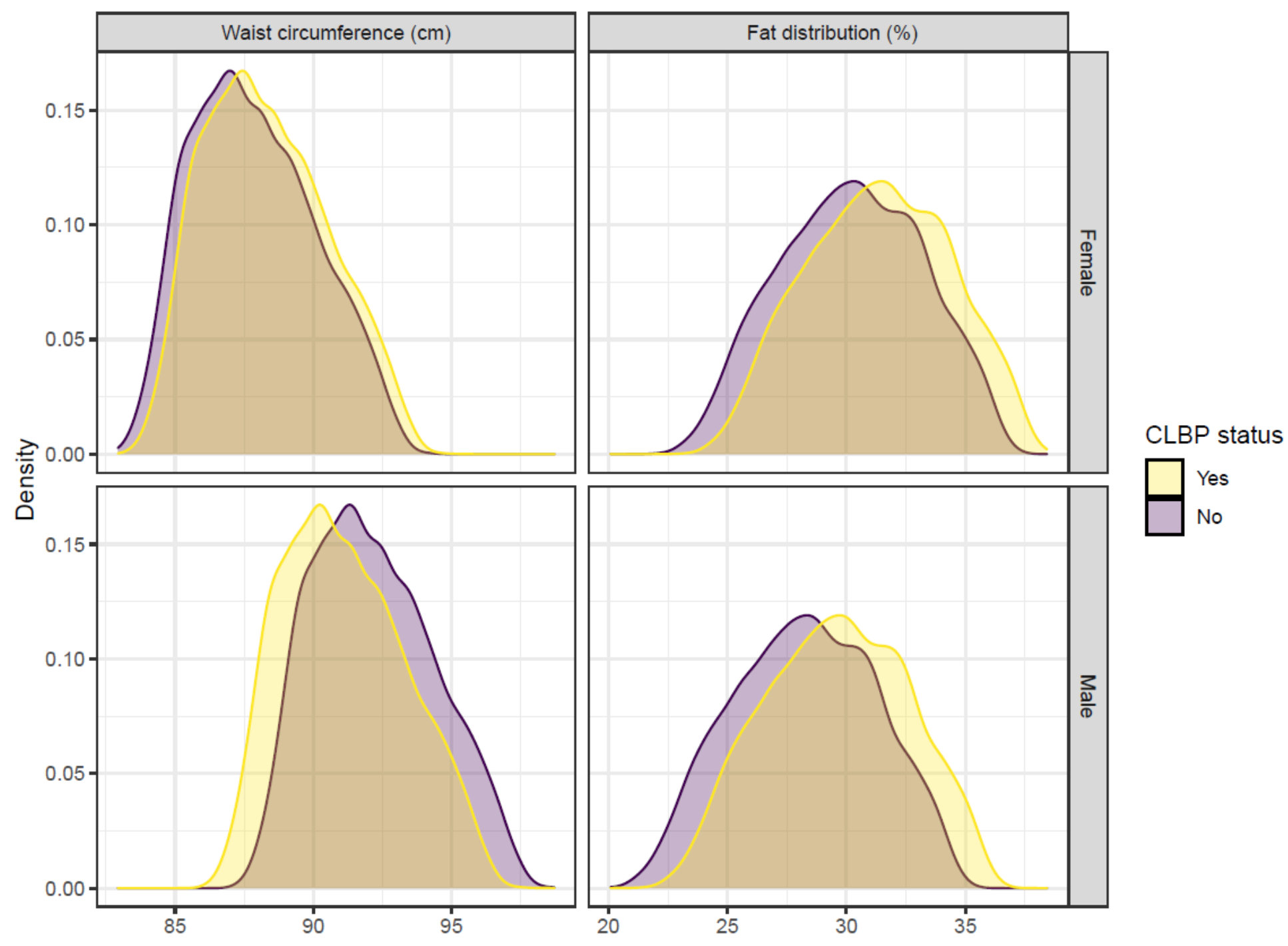

Figure 2

Marginal distribution of waist circumference (left) and regional fat distribution in the lower limbs (right). The value was estimated in people with a BMI higher or equal to $25 \mathrm{~kg} / \mathrm{m} 2$. The difference in the waist circumference was not statistically significant in women $(p=0.328)$, whereas it was among men $(p<0.05)$. The estimated marginal average fat distribution in the lower limbs was statistically significantly higher in the people with CLBP than in those without it, in both sexes. Abbreviations: CLBP, chronic low back pain; BMI, body mass index. 